\title{
Professional Organizations and Healthcare Industry Support: Ethical Conflict?
}

\author{
THOMAS K. HAZLET and SEAN D. SULLIVAN
}

\section{Introduction}

A good deal of attention has been recently focused on the presumed advertising excesses of the healthcare industry in its promotion techniques to healthcare professionals, whether through offering gratuities such as gifts, ${ }^{1}$ honoraria, or travel support ${ }^{2-6}$ or through deception..$^{7}$ Two basic concerns have been expressed: Does the acceptance of gratuities bias the recipient, tainting his or her responsibilities as the patient's agent? Does acceptance of the gratuity by the healthcare professional contribute to the high cost of healthcare products? The California Society of Hospital Pharmacists was recently asked by its members to formulate a policy for an appropriate relationship between the Society and the healthcare industry, addressing these concerns. In formulating its policy, it became clear that the Society depended on healthcare industry support, gathered through journal advertising, fees for booths at its various educational events, and grants for speakers.

On its face, acceptance by the Society of any support would seem to pose problems of bias for its members (and the patients they serve) and to be cost increasing. ${ }^{8}$ With bias come problems with ethical principles of autonomy, beneficence, and nonmaleficence. By engaging in activities that may increase patients' costs, healthcare professionals may induce problems with nonmaleficence, beneficence, and justice.

In the following discussion we evaluate the appropriateness of the Society's policy by exploring the consensus view of advertising and promotion, the role of advertising, how prices are set by the healthcare industry, and the ethical problems that occur at the intersection of advertising practices and healthcare practice and propose some solutions - relevant to the Society's policy - to the observed problems.

\section{A Consensus View of Advertising and Promotion}

The issue of industry promotion has received considerable attention by Congress. During recent hearings of the Senate Labor and Human Resources Committee, testimony was given revealing all-expense-paid trips to Monte Carlo or Acapulco for physician attendance at industry-sponsored educational symposia, inducements of $\$ 1,200$ to physicians for prescribing expensive antibiotics to patients participating in a "clinical study," frequent flyer miles for prescriptions, ${ }^{9}$ or an $\$ 8$ reimbursement to pharmacists for switching patients from one brand of an oral hypoglycemic agent to another. ${ }^{10}$ More subtle inducements have entailed 
inclusion of good prescribers in speakers bureau listings, provision of research monies, and provision of packaged educational symposia to healthcare associations (topic, speaker, festivities, etc.). A common theme in articles written to point out the conflict established by a healthcare professional's accepting these inducements is that they are cost increasing for the therapy provided.11,12

In addition to concerns that healthcare industry promotional activities may be cost increasing, there is the suggestion that the information presented in some promotional activities is biased or one sided. In a study by Wilkes et al., 109 fullpage advertisements in 10 leading medical journals were evaluated using U.S. Food and Drug Administration (FDA) criteria. The authors concluded that the advertisements would, in $44 \%$ of cases, lead to improper prescribing if the physician had no other information than that contained in the ad. ${ }^{13}$ Stern et al..$^{14}$ described a report distributed by the manufacturer of an immunosuppressive agent promoting its use in the treatment of psoriasis - an unapproved use. One hundred dollars was provided to dermatologists completing a quiz on the report. Under current FDA regulations, information contained in labeling (any written, printed, or graphic matter upon or accompanying the drug; generally, the package insert or the information found in the Physician's Desk Reference) or in advertisements must not be false or misleading in any particular or fail to reveal any material fact. Indications that are not FDA approved ("off-label") are considered to be false and misleading. ${ }^{15}$ Although targets of biased advertising protest that they can discern chaff from wheat, ${ }^{16}$ Avorn et al. ${ }^{17}$ showed that physician beliefs about promotional susceptibility and actual prescribing practice differ. They found that physicians relied on promotional information (e.g., advertisements, detail personnel) rather than scientific information available through published clinical trials or review articles. Soumerai and Avorn ${ }^{18}$ also showed that these influences can be countered with "academic detailing," where approved, unbiased information is provided.

Another concern is that industry-sponsored educational events and journal supplements (e.g., symposium issues) may lack rigor and balance. FDA attempts to distinguish between industry-sponsored "educational" and "promotional" activities based on factors such as 1) the "independence" of the event from the sponsor, 2) long-term financial relationships between the sponsor and speakers, 3) control of the agenda and speaker selection, 4) audience selection, and 5) whether lay media versus scientific media representatives are present. ${ }^{19}$ If it finds that an event tends more toward promotion than education, FDA may use its regulatory authority to take action against the sponsoring firm. Although there is a regulatory limitation on advertising content, enforcement may be less effective than desired. The study of published industry-sponsored symposia, where Bero et al. found that the publications frequently had misleading titles and had been subjected to a lower level of peer review than the parent journal, ${ }^{20}$ has findings that parallel those of Wilkes et al.

Industry expenditures for advertising and promotion are substantial. Lazenby and Letsch projected 1991 pharmaceutical marketing expenditures at $\$ 10$ billion on a $\$ 45$ billion sales base, or about $22 \%$ of sales. ${ }^{21}$ Hurwitz and Caves noted that for pharmaceutical firms with high research and development budgets, sales promotion expense may be as high as 30\% of sales: $70 \%$ for "detailing" to physicians, pharmacists, and other healthcare professionals, $27 \%$ to journals. ${ }^{22}$ In a study by Leffler, the influence of informational versus promotional advertising on a firm's advertising to sales ratio was examined. ${ }^{23}$ He showed that returns 
from promotional advertising were high compared with returns from informational advertising.

The consensus view of advertising and promotion is that healthcare industry expenditures are excessive and may be cost increasing. Also, the information provided is biased. Although healthcare practitioners do not believe that they are influenced by advertising and promotions, studies have demonstrated their effectiveness and, for some, their bias.

\section{Role of Advertising}

A contemporary view of advertising is that most of it stresses "puffery" - giving prominence to attributes of negligible value. Few would acknowledge that advertising has a legitimate role in a business enterprise: providing information. Leffler described two polar views of the effects and value of advertising. ${ }^{23}$ For one, the "Harvard View" developed by Chamberlin, advertising is described as a means for creating artificial product differentiation, informational confusion, and in consequence, barriers to market entry by competitors. In such a market, competition would be expected to be decreased and consumer prices increased. This "adverse view" of promotional advertising suggests that it is meant to fool consumers ${ }^{24}$ into selecting a product that, were they better informed, they would not choose. If two products are viewed as perfect substitutes (e.g., an otherwise identical generic and brand-name drug), price competition will tend to hold down the consumer's price. If advertising succeeds in differentiating the two products by suggesting quality difference, the consumer may be willing to pay a higher price for the perceived quality difference. Promotional advertising can also saturate the consumer so that existence of the lower priced product is not appreciated.$^{25}$ The other view, the "Chicago View" developed by Telser, stresses the value of advertising in providing information, promoting competition, and in select markets, lowering consumer prices. ${ }^{26}$ This "partial view" of advertising suggests that it provides consumers "information" about a product's existence, availability, price, and attributes such as quality. Informational advertising reduces the consumers' search costs, ${ }^{27}$ allowing them to better select between manufacturers. Price competition is fostered with informational advertising. ${ }^{28}$

Can these polar views of advertising be applied to healthcare promotion? As noted by Kessler and Pines, the FDA can take regulatory action against manufacturers that promote unapproved drug uses, but the distinction between dissemination of information and promotion may be subtle. The FDA has been struggling with the distinction for some years and has offered several iterations of a Draft Policy Statement on Industry-Supported Scientific and Education Activities. ${ }^{29}$ In the Draft Policy, the FDA acknowledged " $[t]$ wo important sources of information on therapeutic products . . . (1) activities (programs and materials) produced by the companies that market the products and (2) independent scientific and educational activities, such as continuing medical education. ${ }^{30}$ The FDA attempts to distance itself from regulating scientific and educational activities of manufacturers but emphasizes its authority over nonscientific promotional activities.

Two kinds of advertising have been described: the promotional type, where quality differences of little merit are emphasized, and the informational type. The FDA's policies, in effect, attempt to regulate the former but not the latter. 


\section{Price of Products - Healthcare Industry Behavior}

How do the promotional activities of the healthcare industry influence the price of its products? A description of the pricing behavior of the healthcare industry demands both basic concepts from disciplines such as financial management and cost accounting and some specific information about the industry itself. However, firm-specific information on price-setting behavior is largely proprietary. ${ }^{31}$

A simplified description of the healthcare industry's price-setting behavior includes the following sequence. Firms have various costs of doing business that are often described as "fixed" and include expenses such as administration, research and development, and marketing. "Fixed costs," a concept derived from the accounting literature, are those that one expects to incur in the short run and that are independent of manufacturing volume given the firm's production capabilities. In making a decision to pursue a new product, the firm evaluates the cost of acquiring or producing the product, the price it expects it will be able to charge for that product, the number of units likely to be sold, and the product's contribution to fixed costs. If the profit the firm can make by selling the product under these conditions meets management goals, the project goes forward. ${ }^{32-34}$ In this sequence, the firm makes its decisions about advertising expenditures (as a part of marketing costs) in advance of its price-setting decision. This decision is premised on the firm's experience in its market: it may choose to attain (or maintain) primacy by outspending its competition, thus creating barriers to market entry by new firms, or it may respond to the level of advertising of competing firms in its market. Yet such spending - whether on marketing, research and development, corporate salaries, etc. - is tempered, ultimately, by the price the firm believes it can charge for its product.

Many descriptions of the healthcare industry's pricing behavior tend to lump its many segments in what is presumed to be a homogeneous group. Yet this industry is composed of many discrete subgroups that are differentiated by the unique character of its products. Uniqueness confers market power and increases the price that the consumer must pay. When consumers have more choices, the price they are willing to pay for the product figures more prominently in the selection. Many of the important commodities available in the healthcare industry are pharmaceuticals and medical devices. The pharmaceuticals market includes drugs available directly to the consumer, i.e., those purchased "over-the-counter," and those where the patient's agent (physician, surgeon, dentist, etc.) makes the selection, i.e., prescription or "legend" drugs ("legend" refers to an FDA labeling requirement that prescription-only status be declared on the product's label). The percent of total output for a market manufactured by the top firms is referred to as "concentration ratio," e.g., the four-firm or the eight-firm concentration ratio. Based on the 1982 Census of Manufacturers from the U.S. Department of Commerce, the four largest drug companies manufacture $26 \%$ of total output; the eight largest firms account for nearly $41 \%$. Drug manufacturers do not generally compete with one another on an industry-wide basis; further differentiation is maintained by the therapeutic uses of the drug. For example, the four-firm concentration ratio for duodenal ulcer therapy is greater than $80 \%$, and the four-firm concentration ratio for human recombinant insulin is $100 \%$. High concentration ratios indicate an anticompetitive structure for the industry. Economic theory suggests that if concentration ratios are high, implicit collusion (keeping prices in line with those 
of the competition) is more likely to occur. At the very least, coordination of pricing is easier to manage.

Three other market segments are of note: new drugs, "me-too" drugs, and generic equivalents. Patent protection provides innovator firms with monopoly power (and monopoly prices) for the duration of the patent, and often long afterwards. ${ }^{35}$ These firms have made major investments in research and development and often justify their high prices by these costs. Other firms copy innovator firms' drugs, using minor chemical manipulations to evade the innovator's patent. These "me-too" drugs have lower research and development costs, although introductory prices for "me-too" drugs tend to be higher than for the innovator product. ${ }^{36}$ After patents expire, U.S. firms are allowed to produce generic equivalents with a much lower regulatory burden than that for innovator drugs. Other countries, such as Canada, ${ }^{37}$ mandate cross-licensing of innovator drugs so that generics are available during the term of the innovator's patent protection. In contrast to the innovator and "me-too" market segments, firms are more likely to compete on price in the generic market segment, and consumer prices are likely to be lower. Note, however, that the U.S. innovator rarely competes on price with the generic equivalent.

The market structure we have described is an oligopoly - a structure in which entry of new firms is difficult (barriers are created by high research and development expenses, high advertising expenditures, and major regulatory hurdles) and few firms compete with one another. ${ }^{38}$ As described by Tirole, it is a market where prices are higher than if the barriers (such as advertising) were lower. But he cautioned: ". . . such correlations should not be interpreted as causal relationships. Advertising does not increase profits, and profits do not generate advertising." 39

\section{Does an Ethical Basis for Organization-Industry Conflict Exist?}

Nonscientific promotional advertising may induce less-than-optimal prescribing practices and may be cost increasing to the consumer. In contrast, dissemination of unbiased information may be cost decreasing and may lead to improved outcomes. Given that advertising can have price and quality consequences to consumers, what ethical principles should guide the Society in structuring its relationship with the healthcare industry? We examine the tetrad of ethical principles ("Georgetown mantra" ${ }^{40}$ ) popularized by Beauchamp and Childress ${ }^{41}$ respect for autonomy, nonmaleficence, beneficence, and justice.

In fostering autonomous decision making, the healthcare professional, in providing information to or making judgments for patients, has obligations to avoid controlling constraints and to make full disclosure: "Because of the unequal distribution of knowledge between professionals . . . and patients ... the principle of respect for autonomy entails that professionals have a prima facie obligation to disclose information, to ensure understanding .... and to foster adequate decision making. ${ }^{41}$ A professional's reliance on biased information or acceptance of gratuities - thereby establishing an obligation with the giver that may be in conflict with or prevail over the professional-patient relationship ${ }^{42}$ - seems to violate the principle of autonomy. By extension, participation by a society representing professionals in activities yielding biased information seems also to violate this principle for patients served by society members. 
The second principle of nonmaleficence - one ought not to inflict evil or harmis similarly violated through reliance on biased information. In selecting a course of therapy for a patient, the professional is expected to make an "optimum" choice, where time to desired outcome, side effects, and costs are minimized. If the choice is less than optimal, then avoidable harm may befall the patient.

The third principle of beneficence - preventing or removing evil or harm, promotion of good - suggests a direct obligation to provide best information and to avoid side effects or cost-increasing relationships. Beauchamp and Childress noted a further obligation in beneficence, that of seeking the best balance between benefits and unavoidable harms. Informational bias or conflicting obligations undermine the professional's abilities to make the best choice.

The last principle is that of justice-fair allocation of burdens and benefits. Chren et al ${ }^{42}$ assumed that advertising, including gifts such as beach bags, trips, or textbooks, is cost increasing and noted, "it is unjust to have a system in which patients pay for gifts that benefit doctors and drug companies." They suggested that the injustice is worsened by wealth disparities between patient and physician. Their assessment seems to be congruent with violations of Rawls's, ${ }^{43}$ principles of equal access and fair equality of opportunity working to the greatest benefit of the least advantaged. Thus, acceptance of gifts or financial support by the healthcare professional, and by extension the Society, from industry may violate the principle of justice.

In the situation described by Chren et al., individual healthcare practitioners are the recipients of industry attention. In accepting whatever largess is offered, it appears that each of the tetrad of ethical principles can be violated. Are there circumstances under which the Society could accept support from a healthcare firm without violating these principles?

\section{Remedies: Formulation of the Society's Policy}

The healthcare industry's advertising activities and their associated costs can have undesirable or desirable consequences, depending on their promotional or information character. Do the policies adopted by the Society (Table 1) provide an ethical basis for healthcare industry support of the Society's educational activities? Most of the elements of the policy are directed toward removing bias from the relationship: multiple company sponsorship, reliance on unrestricted grants-in-aid, Program Committee control of program topics and speakers, and elimination of collateral bias from cosponsorship. One item was provided in recognition that the best speakers on a topic may be biased. Under this circumstance, speaker bias should be disclosed. An item has been incorporated into the program evaluation questionnaire to determine if the audience perceived undisclosed bias, and results from the program evaluation are used in making future speaker selections.

The Society's policy does not address the issue that acceptance of healthcare industry support for educational activities may be cost increasing. In the preceding sections, however, we have presented an analysis that suggests a relationship between promotional versus informational advertising and cost effects (Table 2). This analysis suggests that by confining its industry-sponsored educational events to those that are informational, Society acceptance of industry support for the event is at least neutral and may be cost decreasing. 
Table 1. California Society of Hospital Pharmacists Policy on Industry Sponsorship of Educational Events.

1. Multiple company sponsorship shall be sought for society-sponsored events.

2. The Society proactively solicits healthcare industry support of educational events in the form of unrestricted grants-in-aid.

3. The Continuing Education Program Committee shall select program speakers, topics, and program format with the goal of maximizing objectivity, balance, and scientific rigor of the material presented.

4. Speakers shall disclose affiliations with the healthcare industry per established Society disclosure policy.

5. Material from Society-sponsored Continuing Education programs shall not be used for future promotional activities by anyone, unless express written consent is given by the Board of Directors.

6. The Society shall not cosponsor educational activities with other organizations unless these policies are followed by all such sponsoring organizations.

7. The Program Committee for Society-sponsored events shall determine, through an item in the program evaluation, if there was perception of undisclosed speaker bias. Results of this evaluation shall be reviewed in selecting speakers for future programs.

\section{Conclusion}

We have described concerns that advertising, including informational and promotional types, is biased and cost increasing and suggestions that biased information is both presented and relied upon. Reliance upon informational advertising is reasonable and is at least cost neutral. Advertising costs do factor in the price of products as a "fixed" cost. The healthcare market is highly segmented with opportunities for real and perceived product differentiation. This differentiation shifts consumer or agent preference to higher priced products. If reliance is made on biased information or the agent receives gifts (other than unbiased information) from the healthcare industry, the patient's agent violates several ethical obligations. The Society similarly violates these obligations if it participates uncritically in the distribution of biased information or accepts industry support for this participation. In contrast, the Society, in providing unbiased educational events, can reduce the search costs for information and can contribute to patient welfare. Acceptance of industry support for educational activities following the described policy is appropriate.

Table 2. Influence of Advertising on Price of Products.

\begin{tabular}{lcc}
\hline \hline & Promotional & Informational \\
\hline Cost increasing & Yes & $?$ \\
Cost neutral or decreasing & $?$ & Yes \\
\hline
\end{tabular}




\section{Notes}

1. Chren MM, Landefeld SC, Murray TH. Doctors, drug companies, and gifts. Journal of the American Medical Association 1989;262;3448-51.

2. Randall T. Kennedy hearings say no more free lunch-or much else-from drug firms. Joumal of the American Medical Association 1991;265:440-2.

3. Randall T. Ethics of receiving gifts considered. Journal of the American Medical Association 1991;265:442-3.

4. Randall T. Does advertising influence physicians? Journal of the American Medical Association 1991;265:443.

5. Anonymous. Pushing drugs to doctors. Consumer Reports 1992;57(2):87-94.

6. Hillman AL, Eisenberg JM, Pauly MV, et al. Avoiding bias in the conduct and reporting of costeffectiveness research sponsored by pharmaceutical companies. New England Journal of Medicine 1991;324:1362-5.

7. Wilkes MS, Doblin BH, Shapiro MF. Pharmaceutical advertisements in leading medical journals: experts' assessments. Annals of Internal Medicine 1992;116:912-9.

8. The Society's Purposes and Mission Statement includes items on fostering optimal and responsible use of drug-related technologies, increasing the cost-effectiveness of their use, prevention of improper or uncontrolled drug use, and contribution to educational programs. California Journal of Hospital Pharmacy 1993;5:27-33.

9. Graves J. Frequent-flyer programs for drug prescribing [letter]. New England Journal of Medicine 1987;317:252.

10. The Upjohn Diabetes Cognitive Services Reimbursement Program [letter dated 20 August 1992]. Kalamazoo, Michigan: The Upjohn Company.

11. Waud DR. Pharmaceutical promotions - a free lunch? New England Journal of Medicine 1992;327:351-3.

12. Banks D. Conflicts of interest in pharmaceutical advertising: an FDA perspective. Presented at Ohio State University College of Pharmacy, 22-23 April 1991.

13. See note 7. Wilkes, Doblin, Shapiro. 1992;116:912-9.

14. Stern RS, Arndt KA, Baughman RB. Consensus reports from the convinced: manipulating the information transfer process for drug promotion [letter]. Journal of the American Medical Association 1991;265:30.

15. Kessler DA, Pines WL. The federal regulation of prescription drug advertising and promotion. Joumal of the American Medical Association 1990;264:2409-15.

16. See, for example, correspondence to New England Journal of Medicine following Waud's article (see note 11) on pharmaceutical promotions: "The idea that accepting a shirt-pocket protector valued at 50 cents will sway the clinical judgement of a division chief is patently absurd." New England Journal of Medicine 1992;327:1686-8.

17. Avorn J, Chen M, Hartley R. Scientific versus commercial sources of influence on the prescribing behavior of physicians. American Journal of Medicine 1982;73(1):4-8.

18. Soumerai SB, Avorn J. Principles of educational outreach ('academic detailing') to improve clinical decision making. Journal of the American Medical Association 1990;263:549-56.

19. See note 15. Kessler, Pines. 1990;264:2409-15. Kessler DA. Drug promotion and scientific exchange. The role of the clinical investigator. New England Journal of Medicine 1991;325:201-3.

20. Bero LA, Galbraith A, Rennie D. The publication of sponsored symposiums in medical journals. New England Journal of Medicine 1992;327:1135-40.

21. Lazenby HC, Letsch SW. National health expenditures. Health Care Financing Review 1989;12(2):1-26.

22. Hurwitz MA, Caves RE. Persuasion or information? Promotion and the shares of brand name and generic pharmaceuticals. Journal of Law and Economics 1988;31:299-319.

23. Leffler K. Persuasion or information? The economics of prescription drug advertising. Journal of Law and Economics 1981;24:45-74.

24. Feldstein PJ. Health Care Economics. 3rd ed. New York: John Wiley \& Sons, 1988. It should be clear that, for prescription drugs, the "consumer" - the person making a selection - is not the patient, but rather, is the prescriber, acting as the patient's "agent."

25. Tirole J. The Theory of Industrial Organization. Cambridge, Massachusetts: MIT Press, 1988.

26. Benham L. The effect of advertising on the price of eyeglasses. Journal of Law and Economics 1972;15:337.

27. See note 23. Leffler. 1981;24:45-74. Leffler described the "opportunity cost" of time spent learning about the advantages and liabilities of a new drug. The prescriber could obtain information through reading scientific literature, by attending scientific meetings, from promotions (adver- 
tisements, detail persons), or through actual practice with patients. The information source with the lowest opportunity cost for community-based practitioners is promotions.

28. See note 25. Tirole. 1989.

29. Gutfeld, R. FDA seeks scrutiny of drug industry's role in education (Food and Drug Administration guidelines to prevent drug companies from illegal promotions). Wall Street Journal 1992 Nov. 25: B3(W), B7(E), col. 4.

30. Food and Drug Administration. Draft Policy Statement on Industry-Supported Scientific and Educational Activities. 57FR56412-414.

31. See note 5. Anonymous. 1992;57(2):87-94.

32. Deakin EB, Maher MW. Cost Accounting. 2nd ed. Homewood, Illinois: Irwin, 1987.

33. Brigham EF. Financial Management. Theory and Practice. 4th ed. Chicago: Dryden Press, 1985.

34. Sutton J. Sunk Costs and Market Structure. Cambridge, Massachusetts: MIT Press, 1992.

35. Moore SD. Ciba chooses marketing over betting on super drugs. Swiss company uses reformulation, savvy selling to extend products' lives. Wall Street Journal 1992 Jul. 14: B4, col. 3.

36. Grabowski HG, Vernon JM. Pioneers, imitators, and generics-a simulation model of Schumpeterian competition. Quarterly Journal of Economics 1987;491-525. See note 5. Anonymous. 1992;57(2):87-94.

37. Gorecki PK. The importance of being first. The case of prescription drugs in Canada. International Journal of Industrial Organization 1986;4:371-95.

38. Kohler H. Intermediate Microeconomics: Theory and Applications. 3rd ed. Glenview, Illinois: Scott, Foreman and Company, 1990.

39. See note 25. Tirole. 1988.

40. Pellegrino ED. The metamorphosis of medical ethics. Journal of the American Medical Association 1993;269:1158-62.

41. Beauchamp TL, Childress JF. Principles of Biomedical Ethics. New York: Oxford University Press, 1989.

42. See note 1. Chren, Landefeld, Murray. 1989;262:3448-51.

43. Rawls, J. A Theory of Justice. Cambridge, Massachusetts: Harvard University Press, 1971.

\section{Commentary: Klaus M. Leisinger}

There are and have always been different opinions on what the role of the healthcare industry should be, which kind of marketing practices are considered to be appropriate, and which prices are just. For example, many people in society and government institutions generally consider that prices of pharmaceuticals are too high, whereas those in the healthcare industry are usually of a different opinion. The industry argues that its advertising and promotion are beneficial to both society and the corporate world, whereas critics such as Hazlet and Sullivan argue that it may be biased and cost increasing, potentially violating ethical obligations such as autonomy, nonmaleficence, beneficence, and justice.

Controversial judgements are a natural and positive consequence of plu- ralistic societies, and bias is a natural consequence of individual interests and value judgements. The dogma of the "ethical neutrality" of science and technology, as an uncritical belief, says that science is (ideally) objective. Objectivity here means that the scientist should provide disinterested information about facts and not permit an intrusion of his or her subjective values, i.e., the description, interpretation, explanation, and prediction are scientific activities and should be free of all values, especially ethical values. Serious people, however, have given up this dogma and admit that everybody is committed to certain values that undoubtedly influence the issues explored, questions asked, and range of variables considered. Each advocate of a specific viewpoint can substantiate his opinion by citing and referring to relevant empirical studies. 
The traditional commentary one would expect from somebody associated with the healthcare industry is to contradict the notion of a direct link between advertising expenditures and drug prices. One could argue that the healthcare industry is a highly regulated industry, and pressures from both the marketplace and from governments influence corporate pricing policy. The competitive environment compels the companies to operate efficiently. Similarly, budget restraints and concerns about access to healthcare impel governments to demand delivery of costeffective new drugs. Although a variety of factors influence the ultimate price of a pharmaceutical product, in the United States, the price is determined primarily by the market, whereas in most European countries, it is heavily influenced by government agencies. ${ }^{1}$

Moreover, there is ample empirical evidence on the value of advertising. For example, one can quote a recent unquestionable testimony - the report of the U.S. Government Office of Technological Assessment on Pharmaceutical RED: Costs, Risks and Reward-which cites a study referring to the positive impact of advertising: "advertising and promotion outlays may serve to realize the goodwill inherent in an innovation. The value lies in the innovation itself; promotion, like production and distribution, is necessary to unlock that value." 3

One could also argue that advertising and promotion enhances the competitiveness of the marketplace by providing necessary information to consumers, be they healthcare professionals, regulatory agencies, or patients. Through marketing activities, the industry can inform medical professionals of the products' benefits and risks, promote effective utilization of its products, and inform the public of useful innovations. This again can be seen as improving the transparency of the industry and providing the necessary tools for better decision making by healthcare professionals. So much for the traditional way of looking at things!

Regarding the practices of advertising, the "beauty" may well remain in the eye of the beholder-however, there are definitely limits. In my aesthetic judgement, there can be no beauty at all in practices such as offering frequent flyer miles for prescriptions or cash reimbursements to pharmacists for switching patients from one brand to another, the most blatant examples mentioned by the authors.

But to be fair, one should see that it takes two to tango: the one who bribes and the other who can be bribed. Like Edmund Pellegrino, ${ }^{4}$ I am under no illusion that all healthcare professionals necessarily "share a common devotion to a high-flown set of ethical principles."

As he stated: "We are all too good at rationalizing what we want to do that personal gain can be converted from vice to virtue." ${ }^{5}$ Pharmacists accepting money for switching patients or medical doctors accepting all-expense-paid trips to Monte Carlo to attend an "educational symposium" are not morally superior to those who offer such favors.

My spontaneous proposal with regard to the problem of trips would be to hold educational events in academic surroundings such as universities and not in luxury vacation resorts. This would separate the wheat (those interested in education) from the chaff (those interested in holidays paid by somebody else), and this separation would bring the costs of such symposia down considerably.

Healthcare goods, and especially pharmaceuticals, are not commodities in the sense of other consumer or investment goods. They are used because people are sick or in pain, or because they have physical or mental disorders, or because they are dying. Consumer sovereignty, the freedom to choose or 
refuse a product, is limited in markets of the healthcare industry. The resulting ethical responsibility for all involved in health care, i.e., for regulatory authorities, medical doctors, pharmacists, and particularly industry, is pronounced. Safety and risk/benefit assessments that the healthcare industry makes can have particularly fateful properties: if industry's specialists or managers err, they err not just for themselves and their companies but for the sick people. ${ }^{6}$

A healthcare company is well advised - in addition to strictly adhering to the comprehensive laws governing this industry - to develop corporate policies and codes of conduct, e.g., for its promotional and educational activities. These policies must enforce high standards of communication with the medical professions and with the public. In addition to generally accepted approaches such as the Code of Pharmaceutical Marketing Practices of the International Federation of the Pharmaceutical Manufacturers' Association (IFPMA), the European Code of Practice for the Promotion of Medicines, and the World Health Organization's Ethical Criteria for Medicinal Drug Promotion, company-specific guiding principles should be developed to govern promotional activities. CIBA Pharmaceuticals, to give one example, has developed a Marketing Communication Policy and "Guidelines for Adequate Interpretation and Correct Implementation of the Marketing Communication Policy" to tackle specific issues such as "appropriateness of communication" (e.g., by nonmedical celebrity spokespersons in public media ${ }^{7}$ ), "sponsoring, gifts ${ }^{8}$ and samples" or "hospitality. 9" Their compliance is monitored and controlled internationally by a full-time marketing communication auditor and, in many subsidiaries, by Promotional Quality Improvement and Assurance circles or similar bodies.

Permanent dialogue with medical and consumer groups can help to seek shared understanding about the importance of specific criteria in such codes of conduct, to review them periodically, and to adapt them as necessary.

Are these safeguards sufficient? The hard truth remains: as long as there are human beings making decisions, "corporate misconduct, like the lowly cockroach, is a plague that we can suppress but never exterminate." 10 The suggestion brought forth by Hazlet and Sullivan to formulate a policy of Hospital Pharmacists on Industry Sponsorship should be supported because it helps to create transparency with regard to interests involved in educational events supported by the healthcare industry. If one would have to list the most important factors to prevent blatant unethical behavior of any person or institution, transparency would be at the top of the list.

\section{Notes}

1. Because pricing is a minor aspect of Hazlet and Sullivan's paper, it will not be pursued here in detail. For a detailed presentation of the pharmaceutical industry's point of view with regard to pricing see Interpharma/MPS, eds. Individual Responsibility and Social Solidarity in Europe. A Workable Combination. Basel Medizinisch-Pharmazeutische Studiengesellschaft/Interpharma 1993.

2. U.S. Congress, Office of Technology Assessment. Pharmaceutical RED: Costs, Risks and Reward. Washington D.C.: U.S. Government Printing Office, 1993:102, footnote, 34; OTA-H-522.

3. Hurwitz MA, Caves RE. Persuasion or information? Promotion and the shares of brand name and generic pharmaceuticals. Journal of Law and Economics 1988;31:299-320.

4. Pellegrino ED. The virtuous physician, and the ethics of medicine. In: Beauchamp L, Walters L, eds. Contemporary Issues in Bioethics. 3rd ed. Belmont, California: Wadsworth, 1989: 316-22.

5. See note 4. Pellegrino. 1989:321.

6. Leisinger KM. Corporate ethics. In: Dinkel R, Horisberger B, Tolo KW, eds. Improving Drug Safety-A Joint Responsibility. New York: Springer, 1991:47-57. 
7. The Ciba policy says here, "The use of nonmedical celebrity spokespersons in product communication should be avoided."

8. With regard to gifts, the Ciba policy says, "Gifts offered to health care professionals should primarily entail a benefit to patients or be related to the physician's work or education. They should not be of substantial value and should not represent a financial inducement."

9. The Ciba policy says here, “A reasonable level of hospitality is permissible. . . Hospitality extended to participants in a scientific meeting must be subordinate to the main scientific objective of the event."

10. Gellerman SW. Why "good" managers make bad ethical choices. Harvard Business Review 1986;64(Jul./Aug.):85-90.

\section{* $\quad * \quad *$}

\section{Commentary: Laura Gardner}

\section{Introduction}

Widespread attention is being focused on the healthcare industry's interaction with healthcare professionals in the promotion of pharmaceuticals and other types of products. The main area of concern is the societal impact of various promotional activities, i.e., the amount and direction of the effect of such activities on prescription costs and the ethics of promotional activities vis-à-vis their influence on physician prescribing behavior. These issues have led to the development of the California Society of Hospital Pharmacists' new policy. The Society's concerns in developing this policy mirror those of an increasing number of medical societies, including the American College of Physicians, the American Medical Association, and the Association of American Medical Colleges. ${ }^{1-3}$

Drs. Hazlet and Sullivan's discussion of the ethical considerations and cost impact of the industry's promotional activities provides the contextual background for the California Society of Hospital Pharmacists' policy. My commentary further explores the ethical and cost issues with particular emphasis on the complex ethics of the patientphysician contract and develops a generalized hierarchical framework for ranking the societal acceptability of industry-sponsored promotional activities based on the degree of bias in their informational content and their potential impact on healthcare costs.

The activities included in the hierarchical framework are 1) financial support of educational programs, 2) sponsorship and organization of educational programs, 3) detailing to practicing physicians, 4) distribution of medication samples, and 5) gifts. Financial support of research is another industry activity with ethical implications but is not discussed in this forum. Recent policies developed by medical societies are reviewed in light of the hierarchical framework presented.

\section{The Patient-Physician Contract}

\section{Physician as Agent}

Physicians act on behalf of their patients, selecting among treatment options after considering a patient's medical needs and financial resources. ${ }^{4}$ The physician thus serves as both a clinical and an economic agent of the patient.

Concerns about the effect of promotional activities on physician practice behavior are grounded in the ethics of the physician's role as agent. Physicians are obligated to choose the best treatments for their patients, on the basis of scientific merit, not because they were the recipient of gifts or biased promotional information. Research has provided evidence that the concern about the practice behavior effects of promotional activities is a legitimate one. ${ }^{5-11}$ Physicians appear to be strongly influenced by promotional activities, although they staunchly deny the existence of such influence. ${ }^{12}$ Such massive self-delusion on the part of many physicians is per- 
haps the most worrisome feature of the interaction between the industry and the medical profession because it curtails the ability of the profession to be self-monitoring. ${ }^{13}$ Thus one can argue that promotional activities that influence physician behavior through means other than establishing the scientific merit of the product are a detriment to society.

It is important to consider the tradeoffs that must be negotiated for physicians to fulfill their ethical obligations to patients. For example, given finite economic resources, beneficence (the imperative to provide all possible good for a particular patient) often conflicts with justice (the imperative to provide equally high-quality care to all patients). Neither gifts to the physician nor information provided during promotional activities benefit patients directly. However, in evaluating the acceptability of such activities the potential indirect benefits, such as enhancement of the physician's knowledge of new therapeutic options, must be considered.

One of the main conflicts that physicians face is the need to maintain maximal availability to patients and still spend the time necessary to keep up to date with medical science. Physicians generally agree that they never have as much time as they would like to critically review the latest research studies and clinical articles. The costs (both in time and resources) of acquiring needed information can be substantial. Thus, promotional activities that serve to reduce information costs by providing necessary and valid information to physicians are potentially of benefit to society.

\section{Physicians' Legitimate Self-Interest}

In the literature addressing the physician's role, there has been next to no discussion about the issue of physicians' legitimate self-interest. McCullough pio- neered the argument that the physician's legitimate self-interest is a valid concept that is compatible with the physician's ethical obligations to the patient and must be taken into account in considering the ethics of the patient-physician contract. ${ }^{14}$ McCullough argued that legitimate self-interest comprises both 1) mundane requisites for good patient care such as "the time to study, reflect, and learn and the time to rest and to maintain an alert mind" (p. 12) and 2) obligations to persons and responsibilities outside the medical network, such as family and community. Physicians face a conflict between the need to keep informed so as to provide the best quality patient care and the need to rest, recreate, and spend time with friends and family. These needs are distinct from what McCullough terms "mere" self-interest, including for example, remuneration for its own sake. Thus, one can argue that there is inherent benefit in activities such as educational symposia that permit physicians to balance efficiently the conflicting needs of patient care and their legitimate self-interest.

\section{Hierarchical Framework}

The proposed hierarchical framework ranks industry-sponsored promotional activities on the basis of three characteristics: 1) the potential impact of the activity on prescription costs, 2) the potential degree of bias in the information presented, and 3) the potential of the activity to offset costs at a societal level (see Table 1).

\section{Prescription Costs}

Drs. Hazlet and Sullivan have argued that the industry sets a product's price so as to cover the expected costs of conducting those promotional activities that have been deemed necessary to position that particular product and that the cost 
of promotional activities therefore can be considered a fixed cost for the industry. Thus, regardless of the impact of the promotional activities on physician prescribing behavior, no impact on prescription costs would be expected over the short term. However, over the longer term, any activity that has proven to enhance a company's ability to increase or maintain market share probably will continue to be included in the budget, thus perpetuating a certain level of both fixed costs and product prices.

Thus, for a promotional activity to provide a net benefit to society, it must be shown to offset societal costs over the longer term through some ather means. In fact, promotional activities with an educational component may indeed offset societal costs by reducing physicians' information costs. However, activities with educational content must be further evaluated with regard to their reliability and extent of bias.

\section{Reliability and Bias}

Educational information is lacking in reliability when the material presented is from uncontrolled trials or industrysponsored research that is not peer reviewed by experts outside of the industry or when the information is simply inaccurate. Bias exists when the information is accurate but one sided or incomplete. Information that is lacking in reliability presents no net benefit to society and may result in a product being prescribed in a less than optimal manner, or to patients who will not benefit, or to an extent that is not warranted by the true advantages of the product. Inaccurate information fosters unfair competition that puts companies that play by the rules at a disadvantage.

In contrast, biased information may give a company a competitive advantage within the approved market for the product, i.e., an increased likelihood of that company's product being prescribed in preference to its competitors. This is actually free-market competition at its finest and will be counterbalanced by the promotional efforts of the company's competitors. Activities that present a balanced educational content are of course preferable to those that are biased, but even biased material has value if it is accurate and if the physician is active in seeking alternate points of view.

\section{Potential to Offset Societal Costs}

Information that is accurate but biased may reduce information costs if there is sufficient opportunity for physicians to balance the information received. However, promotional activities that facilitate dissemination of reliable information in a nonbiased manner will reduce information costs to a greater extent and are clearly preferable. Distribution of medication samples is more problematic than promotional activities with education content. Although costs are lower for patients who receive the samples, the cost of the samples is borne by society through the contribution of fixed costs to product prices and because having started the patients on the samples, familiarity and habit may lead physicians to continue to prescribe the higher cost alternatives. ${ }^{15}$ The short-term benefit to selected patients must be balanced against the greater societal cost. The detriment to society would be minimized, however, if physicians were careful to ensure that availability of medication samples did not influence therapeutic choices.

\section{Review of Recent Policy Developments}

Numerous medical societies recently have developed position papers or guidelines regarding the relationship between physicians and the pharma- 
Table 1. Healthcare Industry

\begin{tabular}{|c|c|c|}
\hline Activity & $\begin{array}{c}\text { Targeted } \\
\text { behavioral } \\
\text { outcome }\end{array}$ & $\begin{array}{l}\text { Potential impact } \\
\text { on prescription } \\
\text { costs }\end{array}$ \\
\hline
\end{tabular}

Financial support for medical symposia or CME meetings (includes noncontrolling financial sponsorship or subsidization of the meeting, honoraria for speakers, hosted dinners and social hours, and travel support for attendees; does not include programmatic influence on speaker or topic selection)

Sponsorship and organization of medical symposia or CME meetings, including selection of speakers or lecture topics

Product information presented to physicians during detailing visits or published in journals, monographs, and teaching aids

Distribution of medication samples

Gifts given during detailing visits, giveaways at conventions and conferences, inducements to physicians to recommend formulary placement of a particular product
Increased prescribing Neutral over the short of the company's product through brand recognition, term; longer term may reinforce continued high industry subliminal loyalty promotion budgets

Increased prescribing Increasing over the of the company's product through the influence on clinical judgment short term, if physicians are diverted from prescribing lower cost equivalents; longer term may reinforce continued high industry promotion budgets

Increased prescribing Increasing over the of the company's short term, if physiproduct through the cians are diverted influence of clinical from prescribing judgment

lower cost equivalents; longer term may reinforce continued high industry promotion budgets

Increased prescribing Decreasing, for patients of the company's product through familiarity or acquired habit who receive free samples instead of purchased medication; increasing, if physicians are diverted from prescribing lower cost equivalents or for patients not receiving samples

Increased prescribing Increasing over the of the company's product through brand recognition or subliminal loyalty short term, if physicians are diverted from prescribing lower cost equivalents; longer term may reinforce continued high industry promotion budgets 
Promotional Activities.

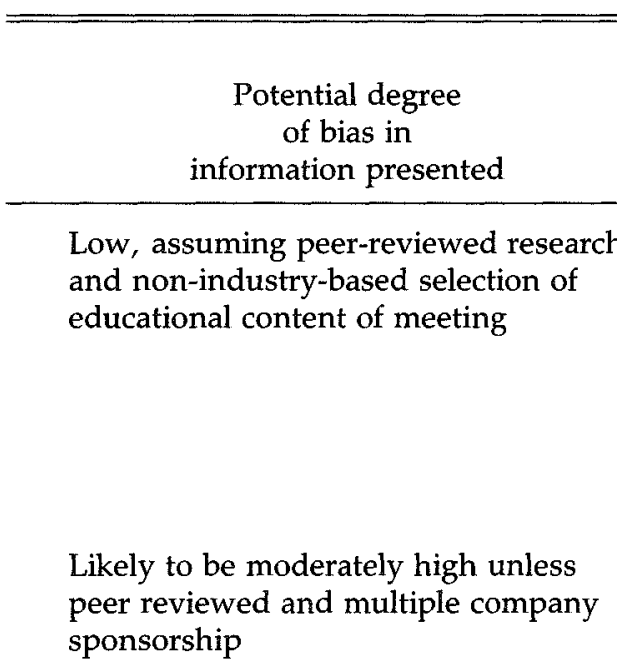
peer reviewed
sponsorship

Likely to be high for any one company but balanced overall

No information is presented

No information is presented

\section{Potential to offset societal costs through decreased information costs}

Net benefit to society

Strong, depending on the quality of the educational content of the information presented

Moderate to strong, depending on the quality of the educational content

Moderate, depending on the quality of the educational content 
ceutical industry. The basis for the guidelines is the recognition that "a responsible and productive alliance between the medical profession and the pharmaceutical industry is unquestionably beneficial to medical progress." 16 In general, the guidelines have the following common elements:

1) Gifts to physicians are not acceptable if there are strings attached, if their value is more than minimal and there is no educational content, or if acceptance might undermine or appear to undermine the objectivity of the physician's judgment.

2) Subsidization of medical education conferences is permissible if payment is not made directly to participating physicians (but instead takes the form of a reduced registration fee, for example), if the conference organizers are not affiliated with the industry, and if there are explicit policies to maintain independent control of program content and selection of faculty.

3) The content of educational programs should be objective and, whenever possible, balanced. Hospitality and amenities should not be excessive. Sponsorship, affiliations, faculty honoraria, and other potentially biasing factors should be disclosed to program participants.

The proposed hierarchical framework appears to fit well with the policy recommendations that the medical societies have developed. The five promotional activities that were evaluated under this framework fall easily into the hierarchy of acceptability, with noncontrolling financial support for medical symposia at the most acceptable end of the spectrum and gifts and inducements to physicians the least acceptable. The framework makes it evident that the main mechanism for offsetting societal costs is through decreased information costs, assuming that the degree of bias in the information presented is taken into account.

Physicians have an obligation to maintain both the appearance and the actual practice of objective decision making and sound clinical judgment. Promotional activities by the healthcare industry can be evaluated by application of the proposed framework of acceptability. When participating in activities with a strong potential for bias, such as detailing visits, physicians are ethically obligated to minimize bias by seeking to balance the information received with information from other sources. The most acceptable promotional activities are those that incorporate an educational component with an unbiased or fully balanced content, thus facilitating a responsible and ethical relationship between physicians and the industry.

\section{Notes}

1. American College of Physicians. Physicians and the pharmaceutical industry. Annals of Internal Medicine 1990;12:624-6.

2. McMurray RJ, Clarke OW, Barrasso JA, et al. Gifts to physicians from industry. Journal of the American Medical Association 1991;265:501.

3. Association of American Medical Colleges. Guidelines for faculty involvement in commercially supported continuing medical education. Academic Medicine 1992;67:616-21.

4. Feldstein PJ. Health Care Economics. 3rd ed. Albany, New York: Delmar, 1988.

5. Avorn J, Chen M, Hartley R. Scientific versus commercial sources of influence on the prescribing behavior of physicians. American Journal of Medicine 1982;73(July):4-8.

6. Bowman MA, Pearle DL. Changes in drug prescribing patterns related to commercial company funding of continuing medical education. Journal of Continuing Education in the Health Professions 1988;8:13-20.

7. Cleary JD. Impact of pharmaceutical sales representatives on physician antibiotic prescribing. Journal of Pharmacy Technology 1992;8:27-9.

8. Morelli D, Koenigsberg MR. Sample medication dispensing in a residency practice. Journal of Family Practice 1992;34:42-8. 
9. Orlowski JP, Wateska L. The effects of pharmaceutical firm enticements on physician prescribing patterns. There's no such thing as a free lunch. Chest 1992;102:270-3.

10. Rosner F. Ethical relationships between drug companies and the medical profession. Chest 1992;102:266-9.

11. Stross JK. Information sources and clinical decisions. Journal of General Internal Medicine 1987;2:155-9

12. Woollard RF. Snake oil and Caesar salad: the ethics of physician and pharmaceutical relationships. Canadian Medical Association Journal 1991;145:931-3.

13. Rodwin MA. The organized American medical profession's response to financial conflicts of interest: 1890-1992. The Milbank Quarterly 1992;70:703-41.

14. McCullough LB. The physician's virtues and legitimate self-interest in the patient-physician contract. The Mount Sinai Journal of Medicine 1993;60:11-4.

15. See note 8. Morelli, Koenigsberg. 1992;34: 42-8.

16. See note 1. American College of Physicians. 1990;12:624.

\section{Commentary: William E. Fassett}

Hazlet and Sullivan's foray into a daunting ethical thicket presents an excellent review of the important considerations regarding industry support of professional societies. I would like to add a discussion of trust to their list of relevant principles. ${ }^{1}$ I will confine my comments otherwise to the distinction they advance between promotional and informational activities. First, I am not sure that the economic distinction they make helps resolve the ethical questions facing professional associations regarding their relationships with the pharmaceutical industry. Second, and perhaps more important, I do not know that any ethical position on this issue can be grounded solely in facts about cost.

As Hazlet and Sullivan noted, the distinction between promotional and informational advertising is fuzzy. Manufacturers must provide factual information about their products to prescribers and dispensers, and they may not mis- lead professionals about the nature of their products. These obligations are ethical as well as legal. However, the test of what is misleading is difficult to apply. For example, not all information about "unlabeled uses" of legend drugs, although legally considered false and misleading, is factually misleading, and one may imagine ethically justified disclosures about these uses. Furthermore, one person's "puffery" is another person's legitimate point of view: what is the information content of "Made in USA"?

However, Hazlet and Sullivan have added a second part to their distinction, that promotional advertising is cost increasing whereas informational advertising is cost neutral at worse. But a key purpose behind promotion is to increase the unit sales of the promoted product, and promotion is very often undertaken because of the economies of scale that result. So, activities in which "quality difference of little merit are emphasized" are cost increasing only if they are ineffective in achieving these economies.

Moreover, not all informational activities are cost neutral. Information about truly new and effective therapies results in these therapies being applied. Newer therapies are often more expensive than older ones, and the availability of newer therapies has helped fuel a rapid increase in healthcare costs. Hazlet and Sullivan may really have meant that promotional activities are distinguishable from informational advertising in that the former increase cost without a corresponding increase in direct medical benefit.

This still leaves us with the problem of intersubjective evaluations of benefits derived from similar products. In addition, it is not clear that direct medical benefits are the appropriate measure of the ethical status of industry advertising. Consider two examples.

Example 1: Activity A increases the 
price consumers pay for Drug D but does not contribute to the safe and effective use of Drug D nor does Drug D's use confer any direct medical benefits for consumers over the use of lowerpriced Competitor $C$. This seems to fit Hazlet and Sullivan's definition of costincreasing promotion. The net result of Activity $\mathrm{A}$ is to increase the profits of the manufacturer of Drug $D$. Because these profits are not merited, Hazlet and Sullivan would prohibit Activity A in conjunction with Pharmacy Society P.

Example 2: Activity B informs prescribers of the fact that Drug $E$ is therapeutically superior to Competitor $C$ for at least some patients; these patients pay more for Drug $\mathrm{E}$ but consider it a worthwhile expense. If we add that the use of Drug $E$ avoids other expenditures by patients who use it, then Activity $B$ seems to become "informational" advertising that is cost neutral or cost decreasing and ethically allowable. Assuming that Competitor C and Drug $E$ have equal production costs, the net result of Activity B is to increase the profits of the manufacturer of Drug E. This increase in profits is merited and is ethically allowable. Activity B could presumably be undertaken in conjunction with Pharmacy Society $P$.

But both examples feature increased industry profits. The industry uses profits from products like Drug D to support the research that results in products like Drug E. They also use profits to support philanthropy and to provide newer drugs to needy patients at reduced rates. Finally, the industry uses its profits to support organizations like Pharmacy Society $P$. These are indirect benefits to consumers.

What finally creates difficulty in supporting the distinction made by Hazlet and Sullivan is the realization that the industry support for Society $\mathrm{P}$ comes only from profits generated by the sales of industry products. In any analysis, the support for the Society is a cost to industry borne by patients. If the support does not result in increased sales or reduced industry expenditures elsewhere, then the support could be discontinued and the money saved used to reduce the price of products. Thus, the justification for industry support of Society $\mathrm{P}$ must rest on the benefits produced by Society $P$, not on the cost of that support.

Drug industry executives have ethical obligations to many persons besides ultimate consumers. Employees and their families depend on the success of the industry, and many argue that the prime obligation of executives is to produce an appropriate long-term return on investment to shareholders. If industry support of Society $P$ results in benefits only for the Society, and none at all to the firms, i.e., its support is utterly untainted by any expectation of benefit, then one can imagine that the industry executives involved are guilty of violating the trust placed in them by shareholders and employees.

Perhaps we will conclude that Society $\mathrm{P}$ should take no industry funds in any form, but that its activities should be entirely funded from its members, who owe their patients the duty of participating in Society $\mathrm{P}$ for the benefits their patients can derive therefrom. Money otherwise spent by the industry can be used to reduce the cost of drugs for patients generally. The cost of Society P's operations will be transferred to its professional members, who may then seek to increase their own incomes by increasing patient charges. U1timately, the ethical justification for these charges rests not in their source, but in their application. Society $\mathrm{P}$, and its members collectively, must be sure that its expenditures provide real benefits to the ultimate payors.

Professionals are ethically impelled to refuse gifts that are little more than bribes to divert their loyalty from their patients to industry sponsors. They 
must also equip themselves with adequate means to actually discern the true value of industy products for their patients. If they continue to accept industry support for professional activities, then they must accept the responsibility to spend that support wisely, and in their patients' actual interests. They may not use an economic distinction between "promotional" and "informational" advertising to conceal the fact that they are accepting industry support that results only and ultimately from their patients' health resources.

\section{Note}

1. Pellegrino ED, Veatch RM, Langan JP, eds Ethics, trust, and the professions: philosophical and cultural aspects. Washington, DC: Georgetown University Press, 1991.

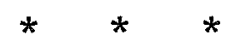

\section{Commentary: Jon R. May}

The article by Hazlet and Sullivan provides a timely and valuable contribution to the literature on the subject of medical ethics. For far too many years, the pharmaceutical industry has attempted to persuade medical and other allied health practitioners to use their products through promotional techniques, such as gifts, honoraria, and travel support, rather than by honest discussion of therapeutic differences between their product and those of competitors. It is apparently easier to garner the good will (and business) of practitioners by showering them with benefits and gifts than by "educating" them to the benefits to their patients by using Company A's product over Company B's product.

Through a review of the relevant literature on the subject of drug product advertising and promotion, Hazlet and Sullivan have amply demonstrated that pharmaceutical industry promotional activities (e.g., payment for attendance at industry-sponsored educational sym- posia and cash inducements for prescribing expensive drugs in promotions designated by the promoter as "clinical studies" but failing to meet the criteria of true clinical studies) are not only cost increasing for the therapy provided but many of them present biased data meant to mislead practitioners. The preponderance of the published studies show that physicians rely more on drug industry promotional information than on their own review of published clinical trials or review articles. It does not take a genius to figure out why that happens - the former approach is quicker and "time is money."

As Hazlet and Sullivan state, the distinction between industry sponsored educational and promotional activities is of concern to everyone, including the U.S. Food and Drug Administration (FDA) who is interested in scientific integrity and who holds the belief that the patient's best interest is first and foremost. The FDA has been concerned for a long time with the promotional activities of pharmaceutical manufacturers/distributors. The FDA intends to monitor the educational activities of the industry more thoroughly in the future, applying the principles spelled out in its recent proposal and highlighted by Hazlet and Sullivan.

The authors have presented adequate evidence that drug industry promotional advertising may induce lessthan-optimal prescribing practices and probably does result in more expensive drugs, thus increasing costs to the consumer. Obviously, neither of these are desirable attributes. As Hazlet and Sullivan state, "In contrast, dissemination of unbiased information may be cost decreasing and may lead to improved outcomes." Thus, it is inevitable that professional associations, such as the California Society of Hospital Pharmacists (CSHP), must adopt a policy that will ensure, to the greatest extent possible, the removal of bias from the 
William E. Fassett

professional association-industry relationship. The seven components of the CSHP Policy Statement ("California Society of Hospital Pharmacists Policy on Industry Sponsorship of Educational Events"), including multiple company sponsorship, reliance on unrestricted grants-in-aid, and Program Committee control of program topics and speakers, constitute a reasonable and workable approach to ensure that only unbiased educational events are presented. In this scenario, the patient is the ultimate winner. 